bones with its shaft. . . The limb would have been blighted very much more if the arrest of growth had taken place at the upper epiphysis of the tibia or the lower epiphysis of the femur. The narrowness and peculiar depth of Scott's head point to some more general congenital error of bonemaking allied to rickets, but certainly not the same as that malady. The vault of the skull is the typical 'scaphoid' or boat-shaped formation, due to premature union of the two parietal bones along the sagittal suture." Creighton goes on to say that this synostosis of cranial bones is characteristic in microcephalous idiots, and he relates that an eminent French anthropologist, who saw a microcephalic skull in the Cambridge Museum of Anatomy, pointed to the scaphoid vault of the crown and the effaced sagittal suture, with the exclamation: "Voilà Walter Scott!" Scott's brain was found to be small in size after death, a fact of little moment in itself, since there is apparently no special relation between cranial capacity, brain weight and ability. Turgenieff and Cuvier had the largest and heaviest brains, Shelley, Scott, Mozart, Gambetta and others, among the smallest.

F. H. Garrison, M.D., Washington, D. C.

\section{"THE ADMINISTRATION OF ARSPHENAMIN"}

To the Editor:-In the letter by Director McCoy of the Hygienic Laboratory, "The Administration of Arsphenamin" (The Journal, July 12, 1919, p. 130), there appears the statement that when only one of several physicians using arsphenamin of the same batch "registers complaint as to the quality of the drug, and the others use it with satisfaction, there seems to be no other conclusion than that the mode of administration in the exceptional case was at fault."

In such case I believe there is at least one other justifiable conclusion: that arsphenamin, perhaps insufficiently dried, will in the course of six months or a year develop toxic by-products in the ampule, and that the amount present will vary with the length of time that elapses before the contents are used and perhaps according to the conditions under which it has been stored. Conceivably such a product may pass the biologic tests at the time of manufacture, and later produce distressing symptoms in human beings. Dr. Hugo Freund, who had been using the "product which enjoys a particularly high reputation" with entire satisfaction, recently reported to me four successive delayed reactions in as many patients. The symptoms were vomiting and an itching dermatitis, occurring from one to four days after administration of the drug. An ampule was examined and was found to be sound, but the contents gave a solution with the characteristic gun-metal tinge due to oxidation. It can be readily demonstrated that arsphenamin will shed metallic arsenic when it has become oxidized, whereas the unchanged base will not do so when reduced with zinc and hydrochloric acid. The so-called nitritoid reactions may also be induced by factors other than dilution and alkalization, however important the latter may be. Ehrlich and Bertheim, in 1912, stated that "salvarsan" contained about 7 per cent. of methyl alcohol, after having been dried for two hours, and in 1918 the two brands of American arsphenamin examined by me were similarly found to contain it. I believed then, as I do now, that this alcohol acts on the base in the ampule, and that a certain amount of methyl arsin may thus accumulate, and when intravenously injected may cause the nitritoid reactions; and according to the amount that may thus have accumulated, the rapidity of injection and the concentration of the solution, cardiac paralysis may result. Kober, working independently, has reached much the same conclusions, and has further succeeded in preparing arsphenamin, free of methyl alcohol, and according to his tests of a lower toxicity. Neo-arsphenamin can be made without the use of methyl alcohol, and this undoubtedly explains the long series of injections reported by Dr. H. McClure Young. (ThE Journal, July 12, p. 131), who used a French brand; in high concentrations, without reactions.

In the decade that has elapsed since the introduction of arsphenamin into therapeutics, the majority of practitioners surely should have been able to master the technic of measur- ing water and counting drops of alkali according to printed directions. I believe there is room for improvement in the drug itself as well as in our methods of administering it.

JoH N B. RIEger, M.D., Detroit.

\section{STETHOSCOPE OR STETHOPHONE}

To the Editor:-Referring to your editorial on Laënnec and the stethoscope, you give the Greek word skoteiv to mean "to examine." Could not the word also be translated "to view" or "to observe"? The ending "scope" being associated with all instruments used for examining by sight, as the telescope, microscope, spectroscope, etc., it seems an error to couple it with: a sound-transmitting instrument, the ending "phone" or "fone" being universally used in the latter connection, as telephone, microphone, etc.

\section{Eugene Kerr, M.D., Towson, Md.}

[COMMENT.-As stated, skorein may mean "to view"; in fact, that is the ordinary meaning of the word, while "to look to, to consider, to examine" are common figurative meanings. Compare, in this connection, "to look into" in English, which has also the figurative meaning "to examine into"; as, for instance, "I will look into the matter." With regard to the question as to whether it would be more accurate to call the stethoscope a stethophone: The term "stethophone" has already been proposed by others who regard it as a more accurate designation for a sound-transmitting instrument, and it will be found duly listed in "The American Medical Dictionary." In regard to $\phi \omega \nu \in i \nu$, the second component part of stethophone, it may be said that it means primarily "to produce a sound or to speak." It does not seem to mean "to sound," as we speak of sounding the depths of the sea; if it did, "stethophone," chest sounder, might be very appropriate. A "stethophone," then, signifies an instrument for making the chest to sound or to resound. Since it does make almost inaudible sounds distinctly audible it may perhaps be said, figuratively speaking, to make the chest resound; but, from an actual standpoint, it has no appreciable effect on the quality of the chest sounds per se. The word "microphone" might have been appropriately used for the stethoscope, since it is an instrument for magnifying sounds. As to the term "stethoscope," since the instrument in question, to which Laënnec himself gave the name, serves to examine the chest, it does not seem inappropriate to call it a "stethoscope," a chest examiner. When, however, the same instrument is used to examine the arteries or the beat of the fetal heart, one has the feeling that the name "stethoscope" is not a broad enough term. It might well be termed a "phonoscope," an instrument for testing sounds, or a "microphonoscope," an instrument for examining scarcely audible sounds, or a "stethophonoscope," when the instrument has been especially adapted for examining the sounds of the chest; or suffering humanity could, if necessary, be inflicted with the term "stethomicrophonoscope," which would mean an instrument for examining the scarcely audible sounds of the chest. This term ought to be "descriptive" enough to satisfy anybody. For short, "stethoscope" does very well. It may be added that the modern Greeks have accepted the term "stethoscope," since they call the instrument $\sigma \tau \eta \theta \sigma \kappa \delta \pi เ o \nu .-E_{D}$.]

\section{CENTENARY OF THE STETHOSCOPE}

To the Editor:-Recently, in looking over a first edition of Laënnec's "Auscultation Médiate" I noticed that it bore the date 1819. The first issues of the book appeared in Paris in September of that year-just a hundred years ago. An editorial in The Journal of August 9 emphasizes this fact. Should there not be some general recognition of this anniversary by the American medical profession? The centenary of the stethoscope! It is at least an opportunity to acknowledge gracefully a part of the great regard we must feel for all France just now, and particularly, with us, for the members of the medical profession in France. If no general act can be accomplished, I would suggest that the various county societies have a Laënnec program early in their fall meetings.

Logan Clendening, Kansas City, Mo.

Instructor in Physical Diagnosis, University of Kansas School of Medicine. 